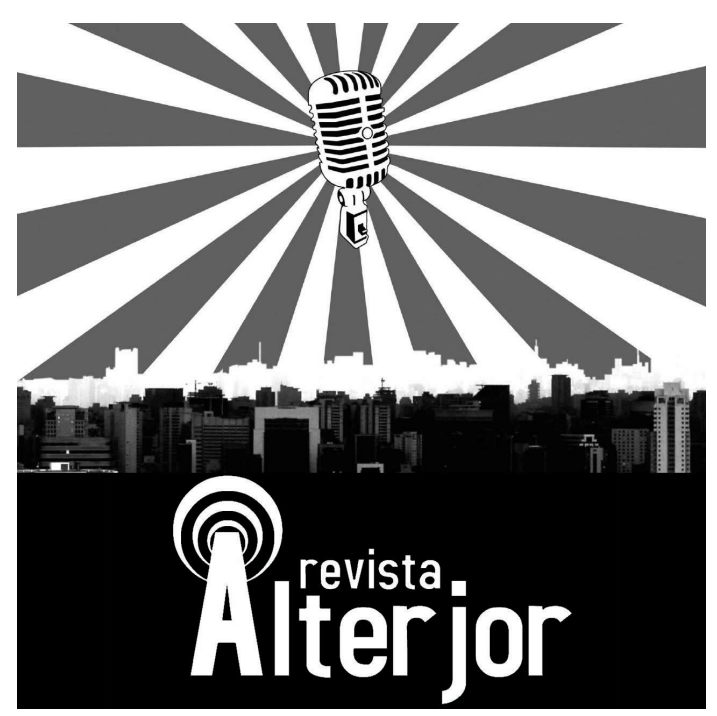

\title{
O PODER ESPETACULAR NO BRASIL ATUAL: UMA TRANSIÇÃO PARA O FASCISMO?
}

Emerson Ike $\operatorname{Coan}^{1}$

RESUMO: O artigo busca compreender o atual estágio do poder espetacular integrado na sociedade brasileira diante de uma aparente transição ao fascismo, conforme a exacerbação do elemento autoritário estatal e a elevação do discurso radical de direita desde o golpe de 2016. Aplicar-se-ão os conceitos, todos repensados na contemporaneidade, de Guy Debord sobre o poder espetacular na formação socioeconômica brasileira e de Florestan Fernandes e Theotonio dos Santos sobre o elemento fascista na ditadura militar de 1964-1985, a qual é exaltada pelo governo presente. Emprega-se o método dialético da teoria crítica da sociedade, pois se pesquisa o objeto em momentos históricos específicos.

PALAVRAS-CHAVE: Sociedade do espetáculo. Poder espetacular integrado. Capitalismo brasileiro. Fascismo. Método dialético.

ABSTRACT: The paper seeks to understand the current stage of the spectacular power integrated into Brazilian society in the face of an apparent transition to fascism, as per the exacerbation of the authoritarian element of the state and the rise of the radical right-wing discourse since the 2016 coup. Rethought in contemporary times, Guy Debord's concepts of spectacular power are applied into Brazilian socio-economic formation, as well as the ideas of Florestan Fernandes and Theotonio dos Santos on the fascist element in the military dictatorship of 1964-1985, which is exalted by the present government. The dialectical method of critical theory is employed, as the research examines the object in specific historical moments.

KEYWORDS: Society of the spectacle. Integrated spectacular power. Capitalism in Brazil. Fascism. Dialectical method.

\footnotetext{
${ }^{1}$ Mestre em Comunicação pela Faculdade Cásper Líbero (FCSCL), na qual é Membro do Grupo de Pesquisa (CNPq) Comunicação e Sociedade do Espetáculo. Mestre em Filosofia e Teoria Geral do Direito pela Faculdade de Direito da Universidade de São Paulo (USP). E-mail: emersonike@hotmail.com
}

\section{Revista ALTERJOR}

Grupo de Estudos Alterjor: Jornalismo Popular e Alternativo (ECA-USP)

Ano 11 - Volume 02 - Edição 24 - Julho-Dezembro de 2021

Av. Professor Lúcio Martins Rodrigues, 443, Cidade Universitária, São Paulo, CEP: 05508-020 


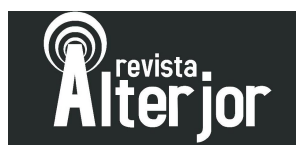

"Em última instância, a evolução destas coisas depende de nós. É da nossa responsabilidade" (Theodor W. Adorno. Aspectos do novo radicalismo de direita)

\section{Introdução}

A presente pesquisa está vinculada ao projeto coletivo "Mídia, Poder e Ideologia na Sociedade do Espetáculo", coordenado pelo professor Dr. Cláudio Novaes Pinto Coelho, na Faculdade Cásper Líbero, São Paulo (SP), que objetiva tratar da questão do poder espetacular, conceito formulado por Guy Debord, na sociedade contemporânea, particularmente a sua aplicação na realidade brasileira.

O conceito de poder espetacular será aplicado em suas formulações do final da década de 1960 - difuso e concentrado - e do final da década de 1980 - integrado - na formação socioeconômica do Brasil como capitalismo dependente.

A partir dessa noção de capitalismo dependente é que se tratará do fascismo na realidade brasileira no período da ditadura militar de 1964 a 1985, o qual o governo Bolsonaro tem como paradigma e, guardadas as diferenças, parece querer reimplantar como "verdadeira democracia". A eventual transição a uma espécie de totalitarismo de direita no Brasil atual permite examinar como naquele período, tido como exemplar pelo atual presidente, certos intelectuais brasileiros pensavam a questão.

Florestan Fernandes e Theotonio dos Santos versaram sobre essa questão, e ambos sustentavam a existência do fascismo no Brasil na ditadura militar de 1964-1985 de uma forma particular, em relação à noção geral - clássica - fascista italiana ou nazista alemã. Florestan Fernandes via o fascismo no Estado autocrático burguês para fins contrarrevolucionários como "totalitarismo de classe", conforme seu conceito de autocracia burguesa. Theotonio dos Santos definia o fascismo como regime totalitário do grande capital, cujo processo de fascistização a partir da ditadura militar se dava em condições específicas, de modo a vislumbrar um "fascismo dependente".

\section{Revista ALTERJOR}

Grupo de Estudos Alterjor: Jornalismo Popular e Alternativo (ECA-USP)

Ano 11 - Volume 02 - Edição 24 - Julho-Dezembro de 2021 Av. Professor Lúcio Martins Rodrigues, 443, Cidade Universitária, São Paulo, CEP: 05508-020 


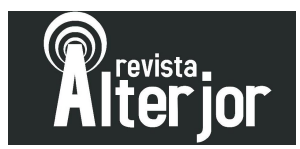

Em face dessas hipóteses, a exacerbação do elemento autoritário estatal e a elevação do discurso radical de direita desde o golpe de 2016 fazem refletir se se caminha para uma espécie de fascismo à brasileira.

O método dialético da teoria crítica será empregado em sua noção básica de uma totalidade concreta em movimento histórico, pois a compreensão dos elementos essenciais definidores das características gerais da vida social, como as formas de poder, exige um exame das situações particulares onde essas características estão presentes.

\section{As formas de poder espetacular no Brasil durante a ditadura militar de 1964-1985}

Para Guy Debord, o capitalismo é uma realidade universal, mundial, e as diferenças entre as formas de poder espetacular correspondem a diferentes graus de desenvolvimento capitalista e da sociedade do espetáculo (Debord, 1997: 38). As formas difusa e concentrada, por ele conceituadas, caracterizam-se de acordo com as particularidades dos países considerados em suas prioridades, produção e poder.

No livro “A sociedade do espetáculo", de 1967, Debord expõe que a forma difusa do poder espetacular é atinente à sua disseminação por toda a vida social, na qual há simultânea produção e consumo de mercadorias e de imagens, e a forma concentrada do poder espetacular está vinculada à ação do Estado, com a produção de imagens a justificar o poder exercido pelo "Líder da Nação". A forma difusa é o poder exercido pelos grandes conglomerados empresariais, em razão da americanização do mundo nas democracias ditas burguesas. A forma concentrada é o poder exercido, acompanhado de violência permanente, em sociedades que Debord denomina como capitalismo de Estado (Debord, 1997: 42-44), quer em países ditos socialistas (como a antiga União Soviética), quer durante o nazi-fascismo (como a Alemanha Nazista).

Embora Debord não tenha se aprofundado no exame das regiões subdesenvolvidas periféricas, por certo ele as veria dominadas do mesmo modo "como sociedade do espetáculo", tais quais as regiões subdesenvolvidas do capitalismo burocrático (Debord,

\section{Revista ALTERJOR}

Grupo de Estudos Alterjor: Jornalismo Popular e Alternativo (ECA-USP)

Ano 11 - Volume 02 - Edição 24 - Julho-Dezembro de 2021 Av. Professor Lúcio Martins Rodrigues, 443, Cidade Universitária, São Paulo, CEP: 05508-020 


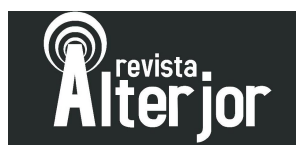

1997: 38), e a sua forma de exercício de poder se daria à maneira das particularidades da formação socioeconômica estudada, i. e., situada historicamente.

Dada a contemporaneidade do livro citado, é possível aplicar os conceitos de poder espetacular difuso e poder espetacular concentrado na realidade social brasileira no período da ditadura militar de 1964-1985. Sob características específicas, pode-se afirmar que as duas formas espetaculares de poder coexistiam nesse período.

A ampliação da base material do exercício hegemônico burguês, com a ocupação do aparelho de Estado pelas Forças Armadas, deu-se no período do chamado "milagre econômico brasileiro", nos "anos de chumbo" da ditadura militar, entre 1969 e 1974, quando se implantou o projeto de desenvolvimento econômico, associado e dependente do capital multinacional - norte-americano em especial -, com o aumento do mercado consumidor para bens de consumo duráveis. A ampliação do mercado consumidor para esses bens, produzidos em sua maior parte pelas empresas multinacionais, fortaleceu a constituição no Brasil de uma sociedade de consumo.

Observa-se um caráter contraditório, pois, ao mesmo tempo em que o regime militar no Brasil incentivava a ação de conglomerados empresariais, nacionais e multinacionais, para a expansão da indústria cultural - poder espetacular difuso -, da mesma forma impunha uma censura rigorosa aos produtos culturais, como uma das expressões do poder espetacular concentrado (Coan, 2020).

\section{A formação socioeconômica brasileira}

Para que se compreenda a sociedade capitalista no Brasil, também deve ser empregado o critério de diferenças entre o universal e o particular.

Em um sistema de notação marxista, é a estas diferenças (e não àquelas uniformidades) que cabe recorrer para explicar a variação essencial e diferencial, isto é, o que é típico da transformação capitalista e da dominação burguesa sob o capitalismo dependente. Só assim se pode colocar em evidência "como" e "por que" a Revolução Burguesa constituiu uma realidade histórica peculiar nas nações capitalistas dependentes e subdesenvolvidas, sem recorrer à substancialização e à mistificação da história (Fernandes, 2006a: 340).

\section{Revista ALTERJOR}

Grupo de Estudos Alterjor: Jornalismo Popular e Alternativo (ECA-USP)

Ano 11 - Volume 02 - Edição 24 - Julho-Dezembro de 2021 Av. Professor Lúcio Martins Rodrigues, 443, Cidade Universitária, São Paulo, CEP: 05508-020 


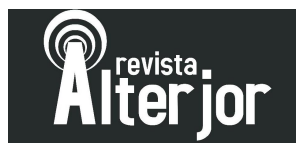

Sobre isso, especifica Theotonio dos Santos:

Ao não considerar os limites do desenvolvimento dependente, a ciência social latino-americana projetou para os nossos países um desenvolvimento que nos conduziria à mesma situação dos países capitalistas avançados. Mas a realidade se mostrou muito distinta, e atualmente obriga este pensamento a realizar uma autocrítica. A compreensão do desenvolvimento latino-americano e das leis que o governam exige superar os limites desta situação condicionante, ou seja, exige superar os limites e os horizontes teóricos e ideológicos da dominação. Exige, portanto, propor a superação do sistema socioeconômico que produz a dependência (Santos, 2018: 63).

A "dependência" é o instrumento para compreender o desenvolvimento do país conforme padrões específicos, dados pela situação de dominação a que está submetido econômico, social e politicamente ao capital internacional. A dependência é uma característica intrínseca do sistema socioeconômico dos países subdesenvolvidos latinoamericanos; é a forma por meio da qual a sociedade brasileira se estrutura; a situação que condiciona e dá ao desenvolvimento do país uma forma particular de produção capitalista em âmbito mundial.

Tal cenário se opera num processo de integração global, substancialmente a partir da Segunda Guerra Mundial, sob o controle hegemônico dos Estados Unidos Imperialismo -, fundado na ideologia da unidade do mundo ocidental cristão contra um inimigo em comum: o campo socialista em expansão. Ele se apoia em uma infraestrutura econômica cuja célula é a grande empresa monopólica multinacional e conglomerada.

O capitalismo dependente é essencialmente excludente em seu crescimento, o que faz aumentar a instabilidade e o desequilíbrio interno da sociedade. Isso obriga a classe dominante a instaurar uma política de força para garantir a sobrevivência do sistema.

A burguesia brasileira é dependente do grande capital internacional, porquanto débil para conduzir autonomamente a transformação capitalista: revolução nacional e revolução democrática. A democracia é restrita, i.e., aberta e funcional só para os que têm acesso à dominação burguesa - o inverso de uma democracia de participação ampliada. O capitalismo dependente se concretiza por meio da superexploração e da autocracia burguesa.

\section{Revista ALTERJOR}

Grupo de Estudos Alterjor: Jornalismo Popular e Alternativo (ECA-USP)

Ano 11 - Volume 02 - Edição 24 - Julho-Dezembro de 2021 Av. Professor Lúcio Martins Rodrigues, 443, Cidade Universitária, São Paulo, CEP: 05508-020 


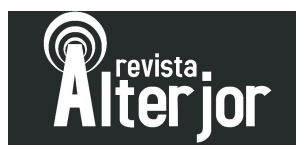

Ele [capitalismo dependente] já não é mais capaz de provocar grandes transformações niveladoras, de sentido nacionalista e revolucionário; não engendra qualquer modalidade de democratização de renda, do prestígio social e do poder, e muito menos qualquer realidade política que lembre uma autêntica democracia burguesa. Se provoca e acelera a descolonização, isso se dá dentro dos limites de uma necessidade econômica imperiosa, pois não se pode modernizar a produção e a circulação sem recorrer ao trabalho livre, à produção de escala e a mercados nacionais. Todavia, a descolonização é contida ao nível social, cultural e político, para que a imensa maioria possa continuar uma presa fácil de uma arregimentação fascista que se inculca "racional", "humana", "cristã" e "democrática" (Fernandes, 1995: 140).

No processo de "revolução" burguesa - sem uma ruptura violenta com as forças sociais retrógadas do antigo regime, típica do modelo clássico -, o golpe de Estado de 1964 deu à burguesia brasileira - por força de uma recomposição conservadora das estruturas de poder - as condições mais vantajosas possíveis para estabelecer uma associação mais íntima com o capitalismo financeiro internacional e para transformar o Estado em instrumento exclusivo seu, tanto no plano econômico quanto nos planos político e social.

Com a ruptura institucional "de cima para baixo", o sentido da dominação burguesa se desmascarou, "deixando a nu sua natureza incoercivelmente autocrática" (Fernandes, 2006a: 257), ${ }^{2}$ pois tinha base na existência de suportes institucionais políticos, econômicos e militares -, a fim de que as forças contestatórias, oriundas das classes desfavorecidas, não conseguissem estabelecer um grau de organização permissivo de disputar os espaços de poder. Com a inibição dessa disputa de espaço de poder pelas forças contestatórias, impediu-se uma possível revolução que rompesse com as estruturas arcaicas do antigo regime, no sentido de uma democratização verdadeiramente burguesa.

Essa dominação submeteu os interesses nacionais aos das grandes corporações das nações capitalistas desenvolvidas, converteu o Estado autocrático em um instrumento da

\footnotetext{
${ }^{2}$ Gabriel Cohn esclarece que a autocracia de que fala Florestan Fernandes "não é sinônimo de 'autoritarismo' - pois este corresponde a uma forma de exercício do poder e não da sua organização - e nem mesmo se confunde com 'ditadura', embora não a exclua. Tem mais a ver com a concentração exclusiva e privatista do poder" (Cohn, 1999: 404) nas mãos de uma classe e sua consequente democracia restrita e de cooptação.
}

\section{Revista ALTERJOR}

Grupo de Estudos Alterjor: Jornalismo Popular e Alternativo (ECA-USP)

Ano 11 - Volume 02 - Edição 24 - Julho-Dezembro de 2021 


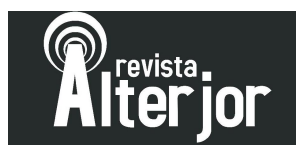

violência organizada, e permitiu a exploração do trabalhador brasileiro e a pulverização da vontade popular. Isso nos termos da "contrarrevolução" preventiva: a capacidade que a classe dominante desenvolveu de antecipar-se no sentido de conter qualquer ameaça de reivindicação das classes trabalhadoras e populares. Essa contenção assumiu feição fascista - de poder espetacular concentrado - na ditadura militar de 1964-1985.

\section{O elemento fascista na ditadura militar de 1964-1985}

O fascismo deve ser igualmente observado de maneira particularizada na sociedade brasileira, uma vez que a realidade nunca será a mesma em diferentes contextos históricos. Florestan Fernandes sustenta que, a despeito de haver uma consideração generalizada do fascismo "clássico" italiano e nazista alemão, não se pode perder de vista, sociologicamente, o fascismo de menor refinamento ideológico, que envolve menor “orquestração de massa" e um aparato de propaganda mais rudimentar, "mas que se baseia fundamentalmente na monopolização de classe do poder estatal e em uma modalidade de "totalitarismo de classe"” (Fernandes, 1981: 16).

Os especialistas se concentram nas formas de fascismo que apareceram na Alemanha e na Itália, onde ocorreu uma grande mobilização ideológica e política das massas e o fascismo exigiu forte apoio popular. Mas existem outras formas de fascismo, nas quais é possível atingir os mesmos fins sem esses meios, inclusive sem mobilização popular, até abafando ou destruindo a mobilização popular (Fernandes, 2011: 324).

Na visão de Florestan Fernandes, na América Latina há, durante a ditadura militar, uma versão complexa dessa espécie de fascismo. Essa variante subdesenvolvida e modernizada de fascismo pressupõe mais uma exacerbação do uso autoritário e totalitário da luta de classes, da opressão social e da repressão política pelo Estado do que uma doutrinação de massa e movimentos de massa. A classe dominante, numa economia dependente como a brasileira, fundamenta seu autoprivilegiamento e sua autodefesa em determinações de natureza fascista, entrelaçadas a formas de violência organizada e institucionalizada nas estruturas de poder e na maquinaria do Estado.

O Estado autocrático burguês na ditadura militar tem essa face fascista que:

\section{Revista ALTERJOR}

Grupo de Estudos Alterjor: Jornalismo Popular e Alternativo (ECA-USP)

Ano 11 - Volume 02 - Edição 24 - Julho-Dezembro de 2021 Av. Professor Lúcio Martins Rodrigues, 443, Cidade Universitária, São Paulo, CEP: 05508-020 


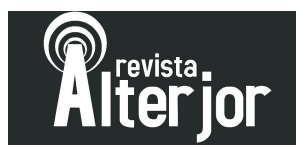

se implanta "dentro do Estado" e nasce de necessidades ultrarrepressivas e da institucionalização da opressão sistemática (sem ela, seria impossível o próprio capitalismo selvagem e a manutenção da ordem, pois os assalariados e os setores pobres se revoltariam, com apoio de divergentes de outras classes. A principal função dessa conexão é a fragmentação do movimento operário e sindical bem como a neutralização de qualquer potencialidade de protesto popular. Essa face não resulta só da existência do arbítrio e do terror; ela está, estrutural e historicamente, na contradição entre uma constituição “democrática" e os 'atos institucionais') (Fernandes, 2019: 89).

Com o Ato Institucional n. ${ }^{\circ}$, de dezembro de 1968 , editado sob a presidência do general Costa e Silva, o autoritarismo do governo dá curso a um processo "linha-dura", nos conhecidos “anos de chumbo", entre 1969 e 1974, sob a presidência do general Emílio Garrastazu Médici. O ato, que vigorou até 1978, concedeu ao Presidente plenos poderes para fechar por tempo ilimitado o Poder Legislativo, intervir em Estados e municípios, suspender por dez anos os direitos políticos de qualquer cidadão, cassar mandatos eletivos, demitir ou aposentar sumariamente funcionários públicos e juízes, suspender a garantia do "habeas corpus", efetuar prisões sem mandado judicial e decretar estado de sítio.

Octavio Ianni sustenta que "havia um diabólico componente fascista na forma pela qual a doutrina de 'segurança e desenvolvimento' aparecia nas técnicas da violência estatal" (Ianni, 1981: 153) na ditadura militar no Brasil. Expõe que a prisão, o sequestro, o sumiço, o assassinato político, junto com o arrocho salarial, a intervenção governamental nos sindicatos urbanos e rurais, a supressão das ligas camponesas, a manipulação do boato e o medo, como técnicas do poder, tudo isso configura uma realidade política fascista (Ianni, 1981: 177).

Com a propagação institucional da ideologia da segurança nacional, apoiada na "doutrina" norte-americana em tempo de Guerra Fria, prevalecia a visão de uma sociedade disciplinada como um quartel militar, em que, declarada a guerra ao "inimigo interno" - os "comunistas" ("terroristas"; "subversivos") -, o que importa é o triunfo sobre ele, a qualquer preço, não importando os métodos pelos quais será obtido, como a tortura ("Brasil: Nunca Mais", 1986).

\section{Revista ALTERJOR}

Grupo de Estudos Alterjor: Jornalismo Popular e Alternativo (ECA-USP)

Ano 11 - Volume 02 - Edição 24 - Julho-Dezembro de 2021 Av. Professor Lúcio Martins Rodrigues, 443, Cidade Universitária, São Paulo, CEP: 05508-020 


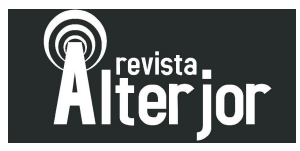

Para Florestan Fernandes, o essencial é que o elemento fascista da ditadura militar representa um duplo bloqueio na esfera política. De um lado, o bloqueio da revolução democrática puramente burguesa, numa posição antiliberal e contrária àquilo que chama de "revolução dentro da ordem": implica a realização das reformas capitalistas, como a reforma agrária, a reforma urbana, a reforma educacional, o combate à miséria, às desigualdades extremas, à fome, à exclusão etc. (Fernandes, 2006b: 48). Ou seja: “o regime fascista se opõe ao movimento da revolução democrático-burguesa, porque teme que a democracia burguesa, em si mesma muito fraca, não possa deter o 'comunismo' e a "rebelião das massas"” (Fernandes, 2011: 324 - destaques no original). De outro lado, há o bloqueio ao movimento socialista, à revolução que não se dá dentro da ordem, mas "contra a ordem". Daí que é: "obstinadamente contra toda forma de revolução democrática, baseada na igualdade e no poder da maioria" (Fernandes, 2011: 324).

Theotonio dos Santos enxerga nesse período uma

transição a uma nova fase política, marcada por um Estado de exceção permanente que ampliava gradativamente seu campo de autoridade e intervenção na sociedade civil. A ideologia fascista se instalava no poder, combinada ou mesmo subordinada a forças conservadoras de matiz liberal-autoritário (Santos, 2018: 80).

O fascismo, segundo o autor, é um regime totalitário e repressivo do grande capital, com forte mística nacional apoiada em ideais raciais, imperiais, tradicionais, sempre anticomunista; é uma ideologia irracionalista que valoriza os elementos culturais, românticos, heroicos e místicos, sempre em vínculo direto com o político e um movimento de origem pequeno-burguesa que se desenvolve em contraposição ao crescimento do movimento revolucionário do proletariado, cujo amadurecimento e capacidade de chegar ao poder só são possíveis quando obtém o apoio do grande capital e se submete à sua estratégia geral (Santos, 2018: 90).

Em sua análise, Theotonio dos Santos sustenta que o fascismo somente se converte em uma força capaz de chegar ao poder e nele permanecer "quando atrai o interesse e o apoio do grande capital" (Santos, 2018: 87). Para esse autor é apenas

\section{Revista ALTERJOR}

Grupo de Estudos Alterjor: Jornalismo Popular e Alternativo (ECA-USP)

Ano 11 - Volume 02 - Edição 24 - Julho-Dezembro de 2021 Av. Professor Lúcio Martins Rodrigues, 443, Cidade Universitária, São Paulo, CEP: 05508-020 


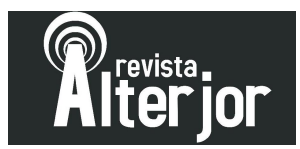

aparente a contradição entre o "Estado fascista", ao refletir os interesses hegemônicos do grande capital, e o caráter ideológico antiliberal do fascismo.

O Estado fascista não se diferencia do Estado liberal em sua essência, mas em sua forma, a qual é importante mas não decisiva. O Estado fascista procura eliminar a distinção entre a sociedade civil e o Estado, estabelece uma adesão incondicional do indivíduo ao Estado, elimina o sistema de partidos e impõe o partido único, não como expressão política dos anseios das suas bases, mas como uma extensão do Estado. Também estabelece o mais rígido verticalismo e militariza a vida social. As formas corporativas devem ser vistas como partes da articulação entre Estado e Partido, de cima para baixo, articulação por meio da qual a ordem econômica e social visa controlar diretamente as contradições da luta de classes no plano econômico e estabelecer uma intervenção estatal de forma mais direta.//Mas o fascismo não elimina a propriedade privada, a organização empresarial e o direito civil burguês, fundamentos da própria sociedade que procuram eliminar no âmbito do direito público (Santos, 2018: 88-89).

Nesse sentido, o fascismo não deixa de ser uma expressão extrema dos elementos constitutivos da ordem liberal capitalista. Daí que:

A polarização entre liberalismo e fascismo, apesar de ser real e de expressar estágios distintos do capitalismo, não é absoluta. Tampouco é absurdo pensar em um regime misto entre fascismo e liberalismo político, no qual este ou aquele aspecto predomine (Santos, 2018: 89).

Theotonio dos Santos defende a existência, na América Latina de modo geral e no Brasil particularmente, de um "fascismo dependente". Nesse caso, o "Estado fascista" é instalado por um golpe militar apoiado pelo grande capital nacional e internacional, e não por um típico "movimento fascista" das massas, nacionalista e antiliberal.

Como expõe:

Portanto, a instauração da ditadura militar não é o fim, mas o começo do processo de fascistização nas condições específicas do capitalismo dependente, em que falta principalmente um apoio de massas ativo a este fascismo, assim como um conteúdo nacional que não pode se evidenciar através de governos essencialmente entreguistas (Santos, 2018: 78).

\section{Revista ALTERJOR}

Grupo de Estudos Alterjor: Jornalismo Popular e Alternativo (ECA-USP)

Ano 11 - Volume 02 - Edição 24 - Julho-Dezembro de 2021 Av. Professor Lúcio Martins Rodrigues, 443, Cidade Universitária, São Paulo, CEP: 05508-020 


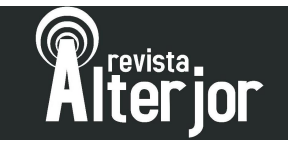

A particularidade do desenvolvimento socioeconômico do Brasil como capitalismo dependente implica o exame de suas determinações, como seu papel submisso em relação ao capital internacional, para a identificação de um modo particular de fascismo no país. Para Theotonio dos Santos o fascismo dependente é a ditadura do grande capital em um país de capitalismo dependente, de conformidade com as configurações acima examinadas.

\section{O poder espetacular integrado no Brasil atual}

Após a ditadura militar, com a "nova república" (1985 em diante), a sociedade brasileira apenas redefiniu para fins institucionais seu caráter autocrático de dominação burguesa. Os expedientes realizados durante o processo de "redemocratização" revelam essa redefinição por meio de uma democracia de cooptação (Coan, 2019). Esse aspecto da sociedade brasileira, "a continuidade da autocracia burguesa, permite a sua identificação como uma sociedade que se enquadra nas características atribuídas por Debord ao poder espetacular integrado" (Coelho, 2015: 23).

Nos "Comentários à Sociedade do Espetáculo", de 1988, Guy Debord sustenta a existência do poder espetacular integrado, que se baseia na vitória generalizada do difuso, porém, sem abandonar as técnicas autoritárias desenvolvidas pelo concentrado em regimes ditos democráticos. A existência do poder espetacular integrado significa a disseminação da sociedade do espetáculo no mundo. Nos países onde vigorava o poder espetacular concentrado, há o aumento da atuação das corporações empresariais na vida econômica e na produção de espetáculos. Nos países onde vigorava o poder espetacular difuso, há o crescimento da atuação repressiva do Estado. Nos países subdesenvolvidos, as especificidades de cada caso concreto são determinantes para avaliar o grau de existência dessa nova forma de poder espetacular.

É possível aplicar de forma particularizada o conceito de poder espetacular integrado na realidade social brasileira, dada a contemporaneidade do livro citado - 1988 . A análise feita por Debord corresponde ao momento de supremacia da ideologia neoliberal em escala mundial. No caso específico do Brasil, já ao ensejo da vitória de

\section{Revista ALTERJOR}

Grupo de Estudos Alterjor: Jornalismo Popular e Alternativo (ECA-USP)

Ano 11 - Volume 02 - Edição 24 - Julho-Dezembro de 2021 Av. Professor Lúcio Martins Rodrigues, 443, Cidade Universitária, São Paulo, CEP: 05508-020 


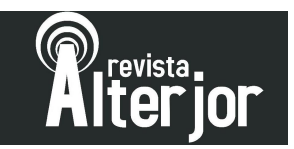

Fernando Collor nas eleições de 1989, houve retrocesso nas conquistas dos trabalhadores na Constituição Federal de 1988, com a defesa da liberdade ampla de atuação para os grandes conglomerados empresariais transnacionais articulados a organismos financeiros.

A incorporação do Brasil ao capitalismo global na década de 1990 em diante manteve o mesmo caráter dependente ao grande capital internacional. No período de governo de Fernando Henrique Cardoso, quando se consolida a autocracia burguesa em sua variante legal-institucionalizada, i.e., a ausência de limite legal de contenção à burguesia, houve desregulamentação dos direitos trabalhistas, além das privatizações das empresas estatais, do corte dos gastos públicos sociais e do aumento de desemprego (Maciel, 2009: 195-210). Para a efetivação de reformas neoliberais, foi empregado o expediente das medidas provisórias, oriundo da antidemocrática supremacia do poder executivo sobre os demais poderes republicanos. Muitas delas se tornaram fato consumado, após sucessivas reedições apenas referendadas pelo Congresso Nacional, sem qualquer espécie de disputa política.

Desde então, há um enfraquecimento dos sindicatos e dos movimentos sociais, assim como dos partidos de esquerda. A alienação política é reforçada, com o esvaziamento da capacidade de compreensão de quem exerce o poder, de que forma, e em nome de quais interesses. A dominação exercida pelo capital financeiro não é reconhecida nem questionada.

Essa configuração ideológica singulariza a classe média brasileira, ao incorporar e propagar a naturalização e a valorização positiva da fragmentação e dispersão socioeconômica, "trazidas pela economia neoliberal e defendidas ideologicamente pelo estímulo ao individualismo competitivo agressivo e ao sucesso a qualquer preço por meio da astúcia, para operar com os procedimentos do mercado" (Chaui, 2016: 20). É nisso que reside o problema da absorção ideológica da nova classe trabalhadora brasileira pelo imaginário de classe média,

absorção que atualmente, no Brasil, se manifesta na disputa entre duas formulações ideológicas que enfatizam a individualidade bemsucedida: a "teologia da prosperidade", do pentecostalismo, e a

\section{Revista ALTERJOR}

Grupo de Estudos Alterjor: Jornalismo Popular e Alternativo (ECA-USP)

Ano 11 - Volume 02 - Edição 24 - Julho-Dezembro de 2021 Av. Professor Lúcio Martins Rodrigues, 443, Cidade Universitária, São Paulo, CEP: 05508-020 


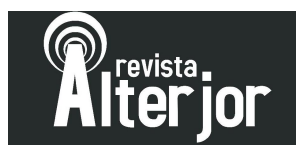

"ideologia do empreendedorismo", da classe média neoliberal (o sonho de virar burguesia) (Chaui, 2016: 20 - destaques no original).

Os governos petistas adotaram compromisso com as regras econômicas neoliberais, para a composição com os adversários nacionais e internacionais e para a construção de alianças a fim de fortalecer a base governista no Congresso, até quando isso foi possível, ou seja, antes do golpe. Suas políticas sociais compensatórias, como programas sociais de redistribuição de renda, sustentadas pelo período de crescimento econômico, ao melhorarem as condições de vida de setores significativos das classes trabalhadoras, foram consideradas "estatistas" demais por setores da burguesia e provocaram fortes reações de amplos setores das classes médias brasileiras, acostumados com a política excludente secular.

Pode-se afirmar que:

No Brasil, o poder espetacular integrado é uma realidade a partir da década de 1990, quando o desenvolvimento capitalista se intensifica com a estabilidade monetária, as privatizações, e a hegemonia ideológica do neoliberalismo. Ocorre também a consolidação definitiva da indústria cultural e do uso das técnicas de marketing, não só para a venda de produtos, mas também na vida política. Essa intensificação do capitalismo aconteceu juntamente com a manutenção pela "nova república" das instituições do aparelho repressivo criadas pela ditadura militar, como as polícias militares, e do próprio papel das forças armadas como mantenedoras em última instância da "ordem social" (Coelho, 2018: 86).

Para caracterizar o caráter concentrado do poder espetacular integrado no Brasil, um exemplo de aparato estatal repressivo preservado da ditadura é o art. 142 da C. F./1988, ao estabelecer que as Forças Armadas "destinam-se à defesa da pátria, à garantia dos poderes constitucionais e, por iniciativa de qualquer destes, da lei e da ordem". O Congresso Constituinte concedeu aos poderes Executivo, Legislativo e Judiciário a prerrogativa de pedir a intervenção das Forças Armadas em assuntos domésticos, para a manutenção da "ordem".

Ainda que haja decisão do Supremo Tribunal Federal sobre a impossibilidade de uso desse artigo para a interferência de um Poder da República sobre o outro, isso não

\section{Revista ALTERJOR}

Grupo de Estudos Alterjor: Jornalismo Popular e Alternativo (ECA-USP)

Ano 11 - Volume 02 - Edição 24 - Julho-Dezembro de 2021 Av. Professor Lúcio Martins Rodrigues, 443, Cidade Universitária, São Paulo, CEP: 05508-020 


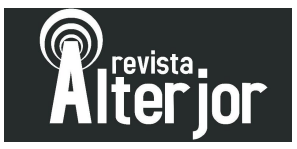

afasta a intervenção militar na "ordem social". A estrutura autoritária da sociedade brasileira, eivada de preconceitos e estereótipos (Coan, 2018), fundamenta a atribuição de sentido às greves de trabalhadores e às manifestações sociais em geral como “desordem", a qual deve ser eliminada pela repressão policial. Fala-se em criminalização dos movimentos sociais.

\section{A exacerbação do elemento autoritário estatal e o discurso radical de direita}

Para ampliar o poder espetacular integrado em sua faceta concentrada na realidade brasileira atual, a burguesia se utiliza novamente do expediente do golpe de Estado - dito impeachment: a derrubada da presidente legitimamente eleita, Dilma Rousseff, por um processo político baseado em artimanhas jurídicas - as chamadas "pedaladas fiscais" como "crime" de responsabilidade - num conluio do Parlamento e da grande mídia, sem a qual não se teria construído a "simulação da ausência de ruptura institucional" (Coelho, 2017: 240).

A reutilização do expediente político do golpe de Estado revela o retrocesso da "democracia" da "nova" república para o modelo ditatorial de 1964, conforme os interesses de grupos do capital financeiro nacional e internacional, setores da oposição, militares do antigo regime e órgãos do aparelho repressivo do estado, para a ação hegemônica a favor da manutenção da classe dominante no poder, para a implantação plena das medidas neoliberais no país a favor da manutenção da autocracia burguesa, já jurídico-institucionalizada. A democracia é cada vez mais restrita, por certo que o conteúdo progressista na C. F./1988 se esvai à luz do dia pelas medidas neoliberais tomadas pelo governo golpista de Michel Temer e pelo seu sucessor na presidência da república, Jair Bolsonaro.

Opera-se uma judicialização da política, cuja arbitrariedade do poder (contrarrevolução preventiva) fica ofuscada pelo espetáculo jurídico-midiático, o que impede qualquer reação popular, pois não são atos autoritários claramente de força armada. Essas práticas radicais atentam contra o Estado de Direito, em razão da quebra do ordenamento jurídico, da ofensa ao princípio da legalidade, com ruptura normativa e

\section{Revista ALTERJOR}

Grupo de Estudos Alterjor: Jornalismo Popular e Alternativo (ECA-USP)

Ano 11 - Volume 02 - Edição 24 - Julho-Dezembro de 2021 Av. Professor Lúcio Martins Rodrigues, 443, Cidade Universitária, São Paulo, CEP: 05508-020 
institucional. Trata-se de situação de exceção. Sob essa ótica, quer no âmbito de validade formal - processual, quer no material - mérito/fatos - das normas:

A consolidação de uma competência altamente ampliada da justiça federal de primeira instância de Curitiba, a reiteração de condenações por teses de domínio dos fatos, o abalo político de divulgação de conversas telefônicas sigilosas entre Rousseff e Lula, a rapidez peculiar dos julgamentos, e ainda, a grande seletividade das investigações e condenações, tudo isso constitui um conjunto de fatos a demonstrar tanto a invalidade formal quanto a material de boa parte de tais operações. Além disso, a noção de golpe jurídico fica ainda mais pronunciada, no campo do próprio direito positivo, quando se olha a sistematicidade das condenações. A seletividade é sua marca patente (Mascaro, 2018: 75).

Nesse contexto, revela-se a fragilidade do controle do Estado, em razão do avanço tecnológico - característica da fase do poder espetacular integrado. Esta se evidenciou nos vazamentos das mensagens obtidas pelo jornal on-line "The Intercept Brasil", que expuseram a parcialidade do então juiz, hoje ex-ministro bolsonarista, Sérgio Moro, e indicaram os problemas legais de seus métodos na Operação Lava - "Vaja" - Jato. As mensagens revelaram a atuação parcial no processo judicial como auxílio e aconselhamento do juiz à parte acusadora e o recebimento privilegiado de informações obtidas pelos investigadores e procuradores federais.

O legado dessa desconstrução do devido processo legal com a legitimação de atos de repressão a pretexto de se coibir a corrupção pela Lava Jato é o autoritarismo. O discurso conservador e reacionário ganhou força ao se associar ao discurso "lavajatista"/midiático de combate à corrupção, à velha política e à esquerda em geral. Discurso presente tanto nas manifestações de rua majoritariamente de classe média de 2013 como nas de 2015, com expressões como "meu partido é o meu país”, típicas de um "nacionalismo fascista", pois contra a mediação institucional, e que fundamentam pedidos de volta da ditadura militar. Não foram diferentes as manifestações de 2016, em favor do golpe de Estado. O mesmo se deu, durante 2017 e 2018, nas reações de apoio aos atos arbitrários da Polícia Federal, do Ministério Público e do Poder Judiciário na Operação Lava Jato, expostos pela grande mídia, os quais culminaram com a prisão de

\section{Revista ALTERJOR}

Grupo de Estudos Alterjor: Jornalismo Popular e Alternativo (ECA-USP)

Ano 11 - Volume 02 - Edição 24 - Julho-Dezembro de 2021 Av. Professor Lúcio Martins Rodrigues, 443, Cidade Universitária, São Paulo, CEP: 05508-020 


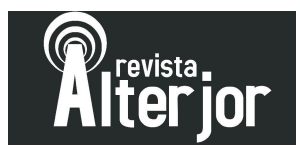

Lula, futuro candidato nas eleições presidenciais, que liderava as pesquisas de intenção de voto, inclusive.

Expõe Alysson Mascaro:

Proponho que os quase trinta anos que separam 1988 de 2016 sejam lidos, na verdade, como modulação de um processo estrutural que remonta a 1964, quando se dão as bases definitivas da relação de dependência entre capital nacional e capital externo, uso do Estado por setores burgueses e políticos assentados em modelos específicos de corrupção na interação entre os negócios públicos e privados, repressão e efetiva militarização do controle das populações e dos movimentos políticos, concreção do judiciário como instrumento do capital e do poder militar, tecnificação acrítica e conservadora dos agentes de Estado (Mascaro, 2018: 80-81).

Conduzido pela burguesia nacional e internacional e por segmentos populares instigados ao conservadorismo, o candidato da extrema direita Jair Bolsonaro vence as eleições de 2018. Bolsonaro, além de mostrar a exorbitância de sua autoridade pessoal, dirige o país com um governo de postura autoritária exacerbada. Há manifestações das autoridades na grande mídia no sentido de que, hoje: pretende-se restabelecer da ditadura militar a ideologia do "inimigo interno/comunista" da doutrina da segurança nacional; o aparato policial-repressivo em geral - inspirado em imagens do governante com as mãos fazendo gesto de armas - se prepara para uma situação de guerra civil permanente contra o migrante, o índio, o negro, o favelado, o sindicalista, as organizações de luta por direitos (negros, homossexuais, mulheres etc.), o desempregado, o sem-teto, o sem-terra ("eles" são o agente violento, ameaçam, noite e dia, o "nós" - a unidade ordeira e pacífica da pátria); instaure-se um nacionalismo do "nós" contra "eles", sugerindo que os incomodados deixem o país; pretende-se restituir no país o que existia há cinquenta anos: o estado de exceção e seu caráter repressivo, com censura nas produções culturais, perseguições aos críticos ao governo, uso de violência excessiva em manifestações públicas etc. São louvados torturadores pelos seus atos.

Em meio a uma grave crise sanitária com sérios danos econômicos e sociais ao país, o governo manifesta-se às portas fechadas de maneira antidemocrática, com ofensas a governadores e ao Supremo Tribunal Federal, conforme vídeo da reunião ministerial do

\section{Revista ALTERJOR}

Grupo de Estudos Alterjor: Jornalismo Popular e Alternativo (ECA-USP)

Ano 11 - Volume 02 - Edição 24 - Julho-Dezembro de 2021 Av. Professor Lúcio Martins Rodrigues, 443, Cidade Universitária, São Paulo, CEP: 05508-020 


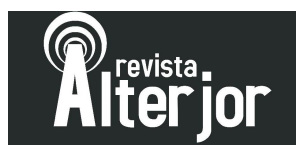

dia 22 de abril de 2020, de divulgação pública autorizada pelo Supremo Tribunal Federal - em inquérito que apura suposta prática de crime pelo presidente da República apontada pelo ex-ministro da justiça Sérgio Moro: o de interferência na Polícia Federal para proteger sua família.

No curso desse governo, já houve um discurso golpista de o Poder Executivo não querer negociar com os outros Poderes da República, em aparição do presidente diante do quartel-general do Exército em Brasília, dirigindo-se a uma aglomeração de apoiadores pró-intervenção militar no Brasil. Chegou-se ao ponto de um ministro-chefe do Gabinete de Segurança Institucional, general do Exército Augusto Heleno, expedir uma nota no sentido de que, em uma eventual ordem judicial - de procedimento legal para busca e apreensão do aparelho celular do presidente pelo STF (em inquérito instaurado por esta Corte para investigar a existência de "fake news" - disseminação de notícias falsas e ameaças - que atingem seus membros), tal qual poderia trazer "consequências imprevisíveis" para a estabilidade nacional. Uma ameaça a uma instituição; uma ameaça de golpe militar de Estado (“golpe dentro do golpe”).

Existe uma forte militarização do poder político estatal, um militarismo redivivo: louvor às Forças Armadas, às polícias militares e à segurança privada. $\mathrm{O}$ inimigo é o socialismo e os movimentos de esquerda - vs. "autênticos brasileiros". Exemplo disso foi o Ministério da Justiça ter pretendido levar a cabo um Dossiê "Ações de Grupos Antifas e Polícias Antifascismo". O governo se intitula "fascista”, portanto.

Uma parcela classe média apoia as regressões econômica, social e institucional advindas desde 2016, com o governo golpista de Temer, somadas ao rebaixamento nos campos da cultura e dos costumes, a partir de 2018, no exercício do mandato presidencial de Bolsonaro. Adota-se o lema: "Brasil acima de tudo, Deus acima de todos" e pretendese instalar uma "escola sem partido" (Gallego, 2018). Tudo para acabar com o que havia de progresso na Constituição Federal de 1988, com feitio de proteção para o bem-estar social, e prosseguir, sob tutela reacionária, com base na repressão para a "segurança".

A organização da subjetividade pela libido repressora, típica nos períodos de crise estrutural capitalista como a que explodiu da crise de 1929 e a atual, decorrente de 2008, enseja por decorrência lideranças de

\section{Revista ALTERJOR}

Grupo de Estudos Alterjor: Jornalismo Popular e Alternativo (ECA-USP)

Ano 11 - Volume 02 - Edição 24 - Julho-Dezembro de 2021 Av. Professor Lúcio Martins Rodrigues, 443, Cidade Universitária, São Paulo, CEP: 05508-020 
tipo também repressor que, em vez de postularem uma ação política investida de libido amorosa (promessas de melhoria das condições de vida, cuidado, proteção), organizam e aglutinam as pulsões individuais e sociais mediante desejo de submissão à autoridade e sua força ameaçadora. Reclamos de segurança, ordem e unidade nacional se sobrepõem aos de emprego, bem-estar social e dignidade (Mascaro, 2019: 31).

Em relação à pandemia mundial de Covid-19, após a confirmação do primeiro caso no Brasil, o presidente disse que o Coronavírus era "fantasia" e ocasionava uma "gripezinha", como expressão do "negacionismo": pensamentos anticientificistas. Enquanto o Brasil computava, em maio de 2020, mais de seis mil mortos pela Covid-19 - um ano depois já seriam mais de quatrocentos mil mortos -, a falta de humanidade do presidente é revelada pelo seu “E daí? Lamento. Quer que eu faça o quê?”.

Marcos Nobre afirma que, em seu projeto autoritário, o mandatário do país utiliza uma racionalidade política cuja lógica é a da guerra e cuja cultura é a da morte que a acompanha.

É uma política da morte que considera conversa-fiada a ideia de que a disputa política se faz sobre um terreno comum compartilhado e compartilhável. Quando a política se torna guerra, só o que existe é uma luta de vida ou morte, em que apenas um lado pode sobreviver. A política da guerra inviabiliza a convivência democrática, em suma. Serve perfeitamente ao objetivo principal de Bolsonaro desde sempre, que é destruir a democracia. E, na pandemia, a política da morte destrói vidas (Nobre, 2020: 10).

Bolsonaro ataca governadores e prefeitos que adotam medidas de isolamento social, quarentenas e "lockdowns", assim como se recusa a produzir um plano de emergência econômica à altura da necessária sustentação de pessoas e empresas. $\mathrm{O}$ caos é o seu método ao limite, num parasitismo antissistema, contra o seu impeachment e visando à sua reeleição em 2022, além de proteger a sua família de investigações criminais diversas. Derrotar o "sistema" significa pôr fim à democracia de "esquerda" após a Constituição de 1988 e instaurar a "verdadeira democracia da ditadura militar": a democracia tutelada.

\section{Revista ALTERJOR}

Grupo de Estudos Alterjor: Jornalismo Popular e Alternativo (ECA-USP)

Ano 11 - Volume 02 - Edição 24 - Julho-Dezembro de 2021 Av. Professor Lúcio Martins Rodrigues, 443, Cidade Universitária, São Paulo, CEP: 05508-020 


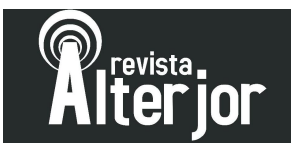

Na avaliação de Marcos Nobre, o projeto de Bolsonaro é de oito anos, sendo que, nesses primeiros quatro anos de mandato, o parasitismo antissistema é um estágio antidemocrático por via eleitoral, e, após uma reeleição, nos outros quatro anos seriam feitas mudanças constitucionais radicais e o populismo autoritário se instalaria em definitivo, suprimindo paulatinamente as instituições democráticas. Daí que o "sistema" é declarado "derrotado e o novo governo autoritário se institui como 'autêntica representação do verdadeiro povo"” (Nobre, 2020: 23).

Segundo tal projeto, tendo como paradigma o período da ditadura militar de 19641985, sua “democracia tutelada” é uma "boa ditadura”, e ele, a melhor opção para o papel de ditador:

em que um grupo autoritário convicto controla eleições e o Judiciário, censura a imprensa, tem o poder de fechar o Congresso e o STF, prende, tortura e mata opositores. Para o grupo dirigente na ditadura, a realização de eleições periódicas, com as severas restrições de qualquer ditadura, servia como uma espécie de termômetro político, era bem ou mal uma maneira de aferir a cada momento o grau de apoio na população, era um instrumento a orientar os governos e os rumos do regime. E ao mesmo tempo também um instrumento de controle da oposição consentida. O projeto de Bolsonaro era impor um modelo como esse ao sistema político. Não seria necessário excluir todo mundo. Apenas quem insistisse em se declarar e em agir à esquerda ou à direita em defesa de uma democracia substantiva (Nobre, 2020: 43).

O reacionarismo é uma variável de sustentação do golpe. Há um ajuste entre a direita neoliberal (partidos tradicionais - MDB, PSDB, DEM -, mídia e economia financeira) e a direita radical (partidos artificiais - PSL - ou ausência deles, interferência na mídia por meio das redes sociais digitais e mesmas mãos financistas). Tal situação está conforme os interesses da burguesia internacional e nacional: atenção aos mercados e interesses financeiros e rentistas; rebaixamento das condições das empresas estatais; desprestígio aos instrumentos de controle social, trabalhista e ambiental; rebaixamento das condições salariais das classes trabalhadoras; privatizações; mercantilização privada de atividades, serviços e bens - previdência social, saúde e educação. "Se um dia advier uma experiência fascista, não virá contra, mas exatamente no bojo e pela direção do capital" (Mascaro, 2019: 26).

\section{Revista ALTERJOR}

Grupo de Estudos Alterjor: Jornalismo Popular e Alternativo (ECA-USP)

Ano 11 - Volume 02 - Edição 24 - Julho-Dezembro de 2021 Av. Professor Lúcio Martins Rodrigues, 443, Cidade Universitária, São Paulo, CEP: 05508-020 


\section{Difieior}

A nova direita no Brasil não é antiliberal - contrária ao neoliberalismo, portanto -, mas sua feição reacionária possui, em alguns pontos, elementos “fascistas”. É preciso ter em conta que, em princípio, o fascismo é antiliberal, assim não seria compatível com o neoliberalismo. A não ser que, ao pretender resgatar os elementos fascistas da ditadura militar, a nova direita do governo Bolsonaro revele, com o neoliberalismo, uma nova modalidade de fascismo: um fascismo à brasileira.

De fato, o presidente da república foi eleito por forças conservadoras e reacionárias para a execução de um projeto autoritário, o qual, além de tomar como referência a ditadura militar implantada no país em 1964, é respaldado pelo capital internacional e nacional com vistas à execução de medidas neoliberais.

Daí que as reflexões de Florestan Fernandes e Theotonio dos Santos sobre a particularidade do fascismo nos países de capitalismo dependente podem fornecer elementos para uma compreensão mais precisa do atual momento de poder espetacular integrado na sociedade brasileira. Nos moldes do que até aqui foi exposto, o advento de algo análogo ao fascismo no país se daria pela implantação de uma ditadura plena, o que, guardadas as diferenças, teria proximidade ao elemento fascista do Estado autocrático burguês de Florestan Fernandes, dada a continuidade da autocracia burguesa no presente, com vistas à contenção de revoluções “dentro da ordem" ou "fora da ordem", estabelecida esta mais em razão de uma possível nova ascensão ao poder de um partido de esquerda do que por movimentos sociais ou populares, pois pulverizados ao longo dos governos neoliberais. Igualmente, com ressalva, teria semelhança a uma espécie de "fascismo dependente" de Theotonio dos Santos, dada a permanência da condição de capitalismo dependente do Brasil, com vistas à constituição de um regime totalitário do grande capital, sem um apoio de massas ativo, assim como um conteúdo nacional que não pode se evidenciar por meio de governos essencialmente entreguistas.

Tanto Florestan Fernandes quanto Theotonio dos Santos, ao mesmo tempo em que anunciavam essa tendência à fascistização das sociedades latino-americanas, sustentavam a iminência do socialismo como horizonte político das classes trabalhadoras.

\section{Revista ALTERJOR}

Grupo de Estudos Alterjor: Jornalismo Popular e Alternativo (ECA-USP)

Ano 11 - Volume 02 - Edição 24 - Julho-Dezembro de 2021 Av. Professor Lúcio Martins Rodrigues, 443, Cidade Universitária, São Paulo, CEP: 05508-020 


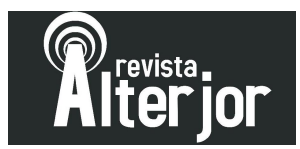

\section{Referências}

ARNS, Dom Paulo Evaristo (prefácio). BRASIL: Nunca Mais. Petrópolis/R. J.: Vozes, 1986.

CHAUI, M. "A nova classe trabalhadora brasileira e a ascensão do conservadorismo". In: JINKINGS, I., DORIA, K., CLETO, M. (orgs.). Por que gritamos golpe?: para entender o impeachment e a crise. São Paulo: Boitempo, p. 15-22, 2016.

COAN, E. I. "Mídia odiosa, alienação política e estrutura autoritária da sociedade brasileira”. In: COELHO, C. N. P. e PERSICHETTI, S. (Orgs.). Política, mídia e espetáculo. São Paulo: Editora Cásper Líbero (recurso digital), p. 141-170, 2018.

COAN, E. I. “A democracia espetacular à brasileira: consenso e coerção". Revista Altejor (Jornalismo popular e alternativo). São Paulo: ECA/USP, p. 63-87, julho-dezembro de 2019.

COAN, E. I. “"Milagre dos peixes'. A censura e a voz de Milton Nascimento na sociedade do espetáculo brasileira". Revista Altejor (Jornalismo popular e alternativo). São Paulo: ECA/USP, p. 127-144, julho-dezembro de 2020.

COELHO, C. N. P. "Em torno do conceito de Sociedade do Espetáculo". In: COELHO, C.N.P. e CASTRO, V.C. (Orgs.). Comunicação e Sociedade do Espetáculo. São Paulo: Paulus, 2006.

COELHO, C. N. P. "Jornalismo e Política na Sociedade do Espetáculo: a Folha de São Paulo e a Legitimação da Ditadura". In: CHAIA, V., COELHO, C., CARVALHO, R. (Orgs.). Mídia e Política: estudos sobre a democracia e os meios de comunicação no Brasil. São Paulo: Anita Garibaldi, p. 9-24, 2015.

COELHO, C. N. P. “Os golpes de 1964 e 2016: poder, espetáculo, simulacro”. Rumores n ${ }^{\mathrm{o}}$ 22, v. 11. São Paulo: ECA/USP, p. 224-249, julho - dezembro de 2017.

COELHO, C. N. P. "Poder e sociedade do espetáculo: a atuação da mídia e a democracia no Brasil" In: COELHO, C. N. P. e PERSICHETTI, S. (Orgs.). Política, mídia e espetáculo. São Paulo: Editora Cásper Líbero (recurso digital), p. 81-93, 2018.

COHN, G. "Florestan Fernandes. 'A revolução burguesa no Brasil'”. In: MOTA, L. D. (org.). Introdução ao Brasil. Um banquete no trópico. São Paulo: Editora SENAC, 1999.

DEBORD, G. A sociedade do espetáculo. Comentários sobre a sociedade do espetáculo. Rio de Janeiro: Contraponto, 1997.

FERNANDES, F. Poder e contrapoder na América Latina. Rio de Janeiro: Zahar, 1981.

FERNANDES, F. Em busca do socialismo: últimos escritos e outros textos. São Paulo: Xamâ, 1995.

FERNANDES, F. A revolução burguesa no Brasil: ensaio de interpretação sociológica. 5. ed. - São Paulo: Globo, 2006a.

FERNANDES, F. Pensamento e ação: o PT e os rumos do socialismo. São Paulo: Globo, 2006b.

\section{Revista ALTERJOR}

Grupo de Estudos Alterjor: Jornalismo Popular e Alternativo (ECA-USP)

Ano 11 - Volume 02 - Edição 24 - Julho-Dezembro de 2021 Av. Professor Lúcio Martins Rodrigues, 443, Cidade Universitária, São Paulo, CEP: 05508-020 


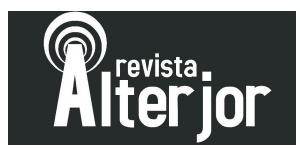

FERNANDES, F. Brasil: em compasso de espera: pequenos escritos políticos. Rio de Janeiro: Editora UFRJ, 2011.

FERNANDES, F. Apontamentos sobre a "Teoria do autoritarismo". São Paulo: Expressão Popular, 2019.

GALlEGO, E. S. (Org.). O ódio como política: a reinvenção da direita no Brasil. São Paulo: Boitempo, 2018.

IANNI, O. A ditadura do grande capital. Rio de Janeiro: Civilização brasileira, 1981.

MACIEL, D. "Neoliberalismo e autocracia burguesa no Brasil". Cadernos CEMARX, no. 5, p. 195-210, 2009.

MASCARO, A. L. Crise e golpe. São Paulo: Boitempo, 2018.

MASCARO, A. L. "Dinâmica da crise e do golpe: de Temer a Bolsonaro". Margem Esquerda, no. 32, p. 25-32, 2019.

NOBRE, M. Ponto-final. A guerra de Bolsonaro contra a democracia. São Paulo: Todavia, 2020.

SANTOS, T. dos. Socialismo ou fascismo. O novo caráter da dependência e o dilema latino-americano. Florianópolis: Insular, 2018. 